\title{
UMA TEORIA DE AVALIAÇÃO DE NEGÓCIOS
}

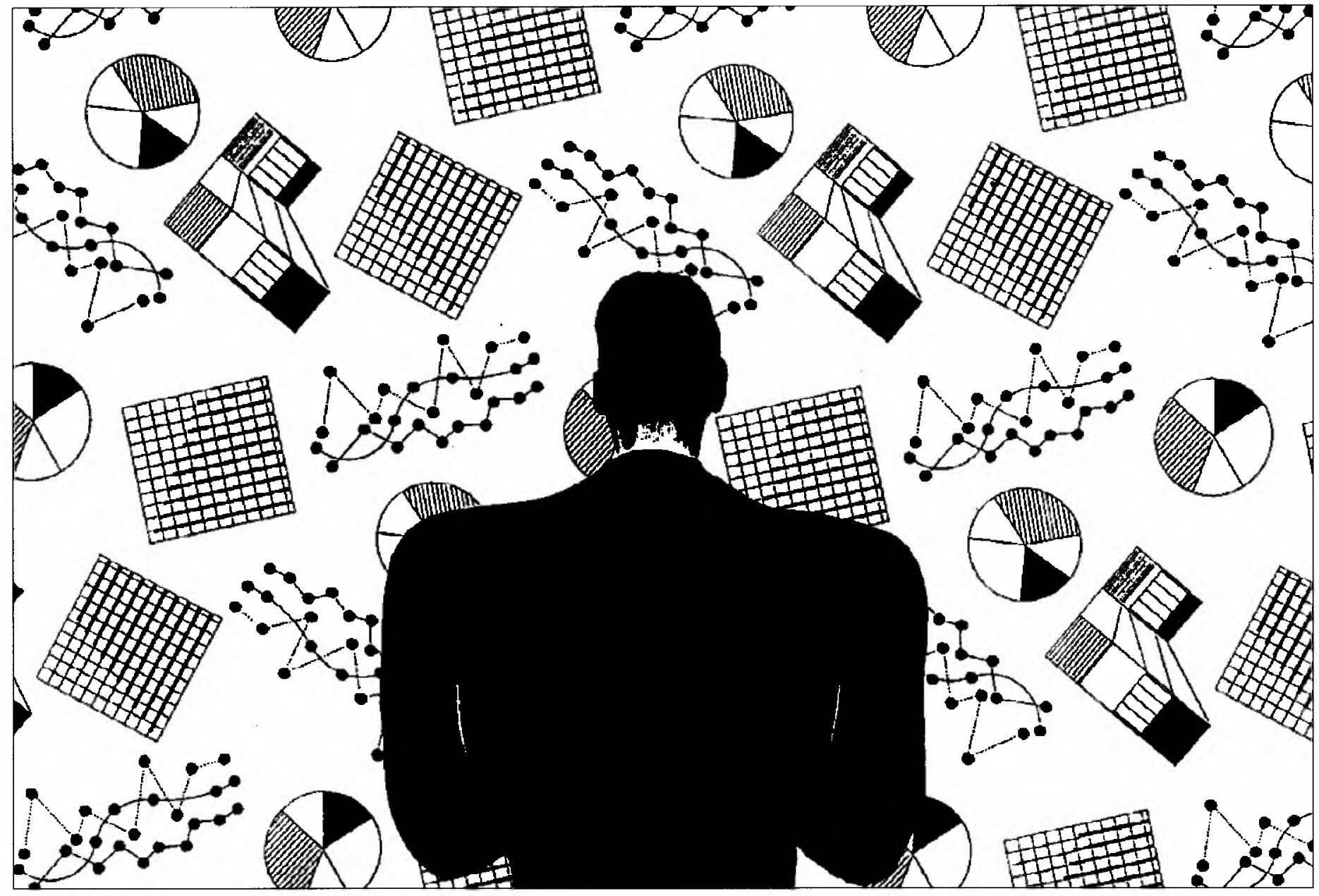

- Mauro Mello

Engenheiro Civil pelo Instituto Militar de Engenharia (RJ), pós-graduado em Matemática pelo Instituto de Matemática Pura e Aplicada (RJ) e consultor de empresas, em São Paulo, nas áreas de finanças e planejamento.

* RESUMO: Este artigo apresenta uma metodologia de avaliação de negócios que se adequa às características do ambiente econômico brasileiro, com imperfeições nos mercados de ações, capitais e produtos. Contudo, também traz alguma luz a problemas teóricos levantados em economias capitalistas mais maduras. Entre esses problemas destacase a diferença entre os retornos obtidos pelos acionistas de empresas adquiridas $e$ os de empresas adquirentes, em processos de aquisições.
* PALAVRAS-CHAVE: Teoria de avaliação de negócios, custo do capital, sinergia, fusões e aquisições, valor.

* ABSTRACT: This paper presents a methodology for business appraisal which can handle the characteristics of the Brazilian economic environment, with imperfect stock, capital and product markets. It also casts some light on theoretic problems, recently discovered at more developed capitalist economies. Among these problems this paper discusses the assymetry of returns to stockholders of acquired and acquiring firms, after takeovers.

* KEY WORDS: Business appraisal theory, cost of capital, synergy, mergers and acquisitions, value. 


\section{OS MÉTOdOS DE AVALIAÇÃO DE NEGÓCIOS}

P arece haver um certo consenso, entre os profissionais de avaliação de empresas, de que o único método conceitualmente correto de determinação do valor de um negócio é o Método do Fluxo de Caixa Descontado (FCD). Esse método consiste em estimar, com um certo conservadorismo, os fluxos de caixa futuros da empresa e descontá-los a valor presente por uma taxa adequada, usualmente denominada "Custo do Capital" da empresa.

A prática, entretanto, tem demonstrado que, tanto no Brasil como no exterior, o valor final pelo qual se dá a transferência de controle das empresas é sistematicamente maior do que o valor do FCD. A mais visível demonstração desse fenômeno são os grandes prêmios, acima do valor de mercado, oferecidos nos takeovers hostis americanos. Ora, se o mercado de ações americano é, como se tem diversas vezes demonstrado, realmente eficiente, o valor corrente das ações é o valor do FCD, o que demonstra que, ao menos em um grande número de casos, o valor do controle de uma empresa é maior do que o do FCD.

Por outro lado, um grande número de estudos tem revelado que processos de takeovers proporcionam retornos significativos para os acionistas das empresas adquiridas enquanto os acionistas das empresas adquirentes não obtêm nenhum ganho estatisticamente diferente de zero. Esse pequeno enígma da teoria financeira contemporânea está detalhadamente apresentado e discutido em Jarrel e Poulsen'.

Nos tópicos a seguir, procuraremos demonstrar que ambos os fenômenos - o viés do $\mathrm{FCD}$ e os retornos diferenciados para as partes de um takeover - estão intimamente relacionados e são compatíveis com os conceitos de eficiência e de racionalidade do mercado de ações.

A teoria aqui apresentada, contudo, não se pretende apenas descritiva, mas também normativa, na medida em que apresenta uma metodologia prática de avaliação de negócios em ambientes de escassez de informação, imperfeições de mercado e, conseqüentemente, 1. JARREL, Gregg \&
POULSEN, Annette. "The Returns to Acquiring Firms in Tender Offers: Evidence From 3 Decades". Financial Manager, outono de 1989.

2. BRADLEY, Michael; DESAI, Anand \& KIM, Han. "The Rationale Behind Interfirm Tender Offers - Information or Synergy?". Journal of Financial Economics, abr. 1983.
$\mathrm{Kim}^{2}$, têm demonstrado que as aquisições são, em geral, realizadas por empresas que possuem sinergia com a empresa alvo. A adquirente, portanto, é alguma empresa do mesmo setor (um concorrente) ou está integrando-se verticalmente (um cliente, um fornecedor) ou horizontalmente (compartilha clientes sem ser concorrente). Podemos tirar daí duas conclusões práticas:

1) Em qualquer hipótese, o adquirente avalia a empresa por um fluxo de caixa futuro maior do que o previsto pelo atual controlador, desde que ambos concordem com premissas realistas e conservadoras para o negócio.

2) O mercado para o controle da empresa é formado pelos seus concorrentes, clientes, fornecedores e vizinhos de setor.

Mesmo nos casos em que uma empresa que não participa do setor é a adquirente, é comum que ela pague um "pedágio" para ultrapassar as barreiras à entrada. Usualmente, o pedágio acarreta um valor superior, até mesmo ao que os concorrentes estariam dispostos a pagar. Foi esse o caso da aquisição da Searle pela Monsanto, em meados de 1985.

Enquanto uma oferta de compra não ocorre, não há nenhuma razão para os atuais acionistas preverem um fluxo de caixa beneficiado por alguma sinergia. A partir do momento em que a oferta de compra se materializa, contudo, o mercado de ações automaticamente reavalia o fluxo futuro. Se esse mercado for eficiente, o comprador não deverá obter nenhum ganho anormal com a transação, ficando o retorno positivo com os antigos acionistas.

Para que se demonstrem as afirmações acima, a teoria de avaliação de negócios que apresentaremos a seguir analisa a transação de transferência de controle como uma operação realizada por dois agentes racionais, que tentam maximizar suas riquezas em um ambiente afetado por risco e incerteza.

\section{TEORIA DE AVALIAÇÃo DE NEGÓCIOS}

\section{Risco e Incerteza}

Toda avaliação é o resultado de um modelo da empresa e do comportamento e preferências dos acionistas atuais e potenciais. Alguns modelos são mais simples, outros mais complexos; alguns consideram explicitamente as diversas variáveis que afetam o valor da empresa, outros não. Mas todos são uma modelagem, isto é, uma simplificação da realidade.

Definimos "risco" como a margem de erro, estimada objetiva ou subjetivamente, para nossas estimativas das variáveis do modelo que são exógenas à empresa e às partes en- 
volvidas na transferência de seu controle: crescimento do PIB, inflação etc. Definimos "incerteza" como a margem de erro das estimativas das variáveis endógenas à empresa $\mathrm{e}$ seus controladores atuais ou potenciais: correlação das vendas com o PIB, margens, custo do capital da empresa, índice $\mathrm{P} / \mathrm{L}$ adequado para a empresa etc. Essas definições não estão em completo acordo com as que usualmente se adota na Teoria Estatística da Decisão mas são mais intuitivas. Por exemplo, costumamos dizer que "existe o risco de uma recessão e estamos incertos quanto à resposta das vendas a uma queda no PIB".

A prática tem consagrado o uso de premissas conservadoras ou de cenários como forma de diminuir o risco do comprador (ou o risco do vendedor, de não vender, quando deveria fazê-lo), enquanto ferramentas estatísticas são mais usadas para lidar com incertezas.

Na Teoria de Avaliação de Negócios que aqui apresentamos, supomos que ambos, comprador e vendedor, podem chegar a um acordo sobre uma geração de recursos, projetada com um grau de conservadorismo que reduza o risco a um nível julgado satisfatório por ambos. Na prática, essa premissa afirma o que já é do conhecimento de todo profissional de fusões e aquisições: é muito difícil vender uma empresa, baseado em sonhos de crescimento e lucratividade, sem uma conexão sólida com o desempenho passado do negócio. Deve-se observar, contudo, que o comprador antecipa uma geração de recursos com sinergias, ao passo que o vendedor projeta um fluxo sem sinergias. A estimativa das sinergias potenciais está exposta no item 2 , a seguir.

A incerteza, portanto, estará reduzida à taxa de desconto da geração operacional de recursos, isto é, ao custo do capital da empresa. Para essa variável, reservamos um tratamento conceitual mais sofisticado, exposto nos itens 3 e 4 , a seguir.

\section{Sinergias}

O trabalho usual de avaliação de empresas inicia-se por uma projeção da geração de recursos futura do negócio. Contudo, essa prática acaba por determinar o valor do negócio para o vendedor, quando, na prática, a venda de uma empresa é uma transação entre duas partes.

Como se viu acima, o mercado para venda de empresas é formado por outras empresas que podem obter um ganho maior do que o atual acionista, caso venham a adquirir o negócio. É impossível saber, a priori, de quanto será essa sinergia, pois ela depende da direção de onde provém o comprador (montante, jusante ou concorrência).
Seguindo a prática usual de realizar estimativas conservadoras, para reduzir os riscos envolvidos no negócio, costumamos incluir, na rubrica "ganhoś com sinergia", apenas reduções de custos e nenhum incremento de receita. Entre esses custos inclui-se a maioria das despesas fixas, como administração, honorários de diretoria e outros.

\section{Custo do Capital}

O custo do capital é, provavelmente, o tema mais complexo e controverso da teoria financeira. Somente em um compêndio de Finanças ${ }^{3}, o$ autor apresenta seis métodos de estimativa do custo de capital e, segundo Lee, Linke e Zumwalt ${ }^{4}$, esses métodos, quando testados empiricamente, não conduzem a resultados estatisticamente correlacionados.

Para tornar ainda mais complexa a situação, na maioria dos casos não podemos, honestamente, aplicar esses métodos à avaliação de empresas brasileiras, quer por falta de informações, quer por não se atenderem aqui às premissas que dão validade aos métodos.

Contudo, apenas arbitrar uma taxa de desconto "usual" ou "adequada" ao nível de risco da empresa é uma atitude não apenas incorreta como incoerente. Incoerente porque a totalidade dos profissionais de avaliação de negócios procura esmerar-se na projeção de resultados, descendo, às vezes, a detalhes minuciosos, para, a seguir, arbitrar a taxa de custeio do capital.

A metodologia de estimativa do custo de capital que iremos expor baseia-se em um trabalho de Michal Kalecki ${ }^{5}$. Esse autor demonstrou haver uma grande correlação entre os investimentos em bens de capital e os lucros futuros na economia americana, no período 1929-1940. Através de tentativa e erro, Kalecki determinou que os lucros de um determinado período correlacionam-se com os investimentos de três meses antes. A relação causal, investimentos gerando lucros a curto prazo, exposta pelo autor, contudo, apesar de válida no âmbito macroeconômico, não é, certamente, verdadeira para um determinado setor ou empresa. Para o nível microeconômico, portanto, adotamos o seguinte modelo:

$$
I_{t}=a \cdot R-b
$$

onde:

$I_{t}$ é o investimento no tempo $t$,

$\mathbf{R}$ é a eficiência marginal do capital adquirido com o investimento $I_{t} e$ $\mathbf{a} \mathbf{e} \mathbf{b}$ são números positivos.
3. LEE, Cheng F. Financial Analysis and Planning. Theory and Application" Reading, Ma.,Addison-Wesley Publ. Company, 1985.

4. LEE, C.F.; LINKE, C.M. \& ZUMWALT, J.K. Alternative Cost-of-Capital Estimation Methods: An Integration and Comparision. Trabalho apresentado no Congresso Anual da Financial Management Association, 1981.

5. KALECKI, Michal. "Theory of Economic Dynamics". Monthly Review Press, New York, 1968, pp. 56-7. 
O conceito de eficiência marginal do capital é definido, nas palavras de seu criador ${ }^{6}$, como "a taxa de desconto que tornaria o valor presente da série de anuidades geradas pelo retorno esperado deste capital, durante sua vida útil, igual ao seu preço de oferta". Keynes observa, ainda, que "a eficiência marginal do capital é definida aqui em termos de expectativa de renda (...) do bem de capital".

Está claro, a partir da equação (1), que para $\mathbf{R}<\mathbf{b} / \mathbf{a}$, o investimento é zero ou negativo. Portanto, b/a é o valor do custo do capital da empresa ou setor ao qual se aplicou o modelo da equação (1).

Como não podemos medir as "expectativas" da renda de um investimento, precisamos obter uma proxy para a variável $\mathbf{R}$, ponto em que nos valemos do trabalho de Kalecki e modificamos o modelo da equação (1) para:

$$
I_{t}=a \cdot M\left(r_{n}\right)-b
$$

onde:

r é o retorno sobre o capital fixo empregado na operação da empresa

$\mathbf{M}\left(\mathbf{r}_{\mathbf{n}}\right)$ é uma média ponderada de $\mathbf{n}$ períodos em torno do período t. Por exemplo, $M\left(r_{n}\right)$ poderia ser:

$$
\begin{gathered}
M\left(r_{n}\right)=\frac{r_{t-1}+r_{t}+r_{t+1}}{3} \\
M\left(r_{n}\right)=\frac{O u}{r_{t-3}+2 \cdot r_{t-2}+3 \cdot r_{t-1}+4 \cdot r_{t}} \\
10
\end{gathered}
$$

A escolha da melhor expressão para $M\left(r_{n}\right)$ é feita pelo critério do melhor coeficiente de correlação $\left(R^{2}\right)$ da regressão obtida para a equação (2). Para que fique claro, definimos $r_{t}$ como:

$$
r_{t}=\frac{L_{t}}{\left(C_{t-1}+C_{t}\right) \cdot 1 / 2}
$$

onde:

$\mathbf{L}_{\mathbf{t}}$ é o lucro líquido operacional do período t $\mathrm{e}$ $\mathbf{C}_{\mathbf{t}}$ é o capital fixo (ativo permanente operacional menos diferido) do final do período $t$.

6. KEYNES, John M. The General Theory of Employment, Interest, and Money. Londres, MacMillan \& Co. Ltd., 1964, pp.135-36.

Na prática, adotamos os seguintes procedimentos para estimar o custo do capital da empresa:
1) Elaboramos, a partir dos valores em moedas nacionais, balanços em moeda constante do maior número possível de empresas do mesmo setor, para um período de cinco a dez anos.

2) Para cada ano, apuramos as médias dos lucros operacionais, dos ativos permanentes operacionais (ex-diferidos) e dos investimentos em ativo permanente operacional das empresas da amostra. Obtemos, assim, os valores de $r_{t}$ e $I_{t}$ de uma "empresa média" do setor.

3) Determinamos qual a média $M\left(r_{n}\right)$ que gera a melhor regressão para a equação (2). Boas regressões, para uma amostra de dez anos, têm $R^{2}$ igual ou superior a 0,65.

4) Determinamos o coeficiente de correlação da mesma regressão, quando aplicada sobre a amostra de todos os pares $I_{t}$ e $M\left(r_{n}\right)$ de todas as empresas. $\mathrm{O}$ objetivo desse passo é determinar se a regressão obtida pode ser aplicada a cada empresa da amostra individualmente ou se a dispersão dos dados individuais é muito grande. Um bom critério para decidir se há muita dispersão é um $\mathrm{R}^{2}$ inferior a 0,45 .

5) Caso o passo 4, acima, apontar que a regressão obtida não é satisfatória $\left(R^{2}<0,45\right)$, calculamos uma nova regressão, agora com duas variáveis explanatórias: $M\left(r_{n}\right)$ e, digamos, o endividamento (dívida financeira sobre ativo permanente mais capital de giro). A nova regressão é estimada com os valores desagregados, isto é, não se trabalha com a média dos valores de investimento, lucro e ativo permanente.

6) A nova regressão pode ser, por exemplo:

$$
I_{t}=0,766 \cdot \frac{r_{t-1}+2 \cdot r_{t}+r_{t+1}}{4}-10,725 \cdot e_{t}-7,801
$$

onde:

$e_{t}$ é o endividamento no período $t$. Se o endividamento atual da empresa a ser avaliada é, digamos, $34 \%$, a regressão passa a ser:

$$
\begin{aligned}
I_{t} & =0,766 \cdot M\left(r_{n}\right)-10,725.0,34-7,801= \\
& =0,766 \cdot M\left(r_{n}\right)-11,448
\end{aligned}
$$

Logo o custo do capital da empresa é

$$
\mathrm{K}=\frac{11.448}{0,766}=14,9 \% \text { a.a. }
$$

Felizmente, o processo, em geral, encerrase no passo 4 , sem que precisemos realizar a regressão múltipla do passo 5 . 


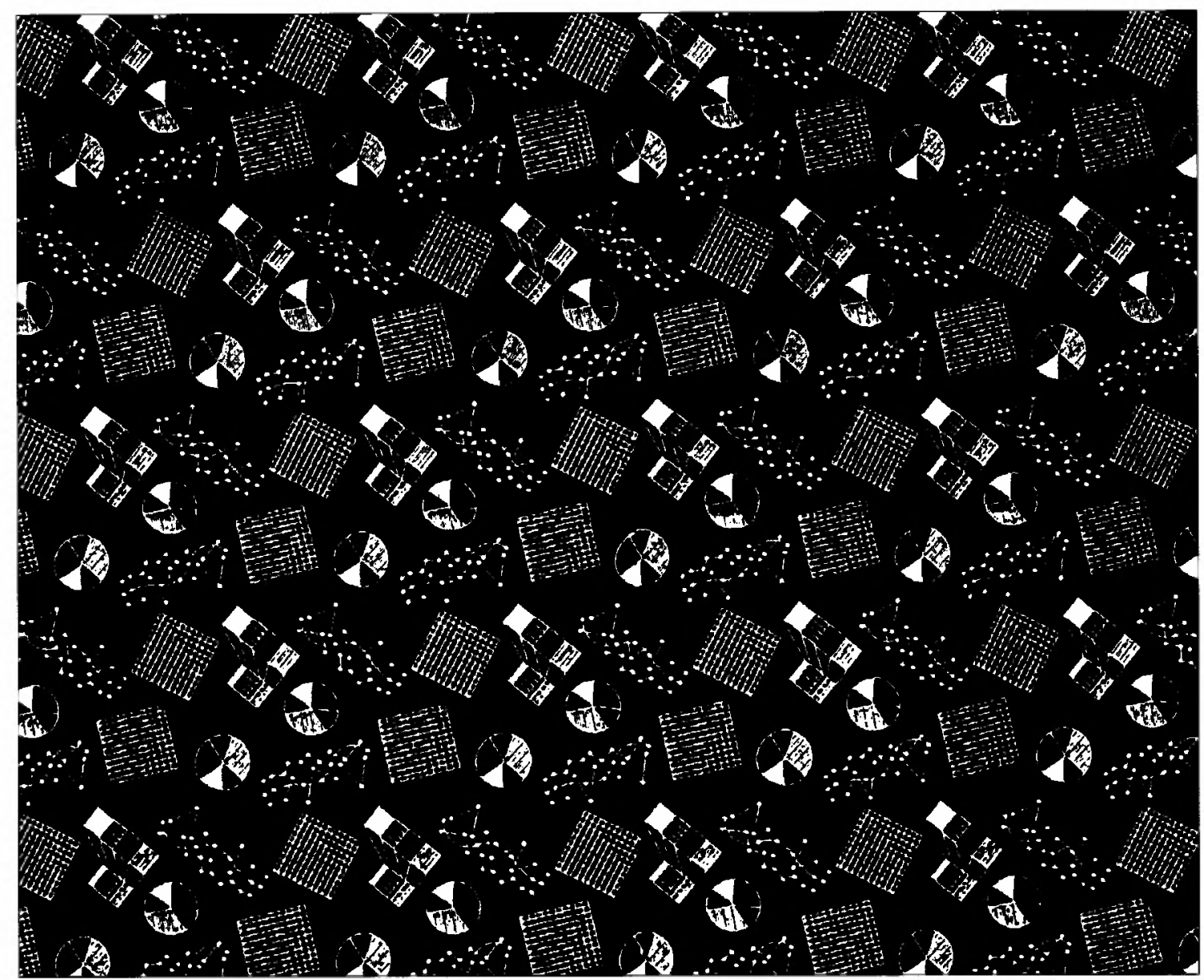

4. O Modelo Probabilístico de Determinação do Valor

Obtida uma estimativa do valor de $K$, o custo do capital da empresa, e sabendo que essa estimativa está cercada de incerteza, devemos utilizar um modelo probabilístico para determinar o valor presente percebido por parte, comprador e vendedor.

O modelo adotado parte das seguintes premissas:

1) À taxa de desconto estimada pela metodologia exposta no item 3 , acima, ambos, comprador e vendedor, ficam indiferentes a realizar a transferência de controle da empresa. Portanto, a probabilidade de $o$ atual proprietário desejar vender o controle da empresa pelo valor presente dos rendimentos sem sinergia, descontados ao custo de capital K, estimado, é de $50 \%$. O mesmo ocorre para um comprador em potencial, com a diferença de que este desconta o fluxo de caixa com sinergia.

2) Para valores menores ou iguais ao do fluxo descontado à taxa de risco zero da economia, $\mathrm{k}_{0}$, o comprador tem $100 \%$ de chance de aceitar a oferta e adquirir a companhia e o vendedor tem $0 \%$ de chance de de- cidir vendê-la.

3) A probabilidade de cada parte decidir realizar o negócio varia linearmente de zero a $100 \%$, em função da taxa de desconto a que se está descontando o fluxo percebido pelo indivíduo.

A figura 1 apresenta, graficamente, o modelo descrito acima.

É fácil perceber, pela figura 1 , que as probabilidades de o vendedor, $P_{v}$, e de o comprador, $P_{c}$ decidirem realizar o negócio são dadas, em função da taxa de desconto dos fluxos projetados, $k$, pelas seguintes expressões:

$$
P_{c}=\frac{k-k_{0}}{2 .\left(K-k_{0}\right)} \quad P_{v}=\frac{k+k_{0}-2 K}{2 \cdot\left(k_{0}-K\right)}
$$

No caso mais simples possível, em que a geração de recursos projetada é uma perpetuidade, podemos facilmente expressar as probabilidades acima em função de valores monetários, ao invés de taxas de desconto. Obteremos, então, uma função como a da figura 2. Nessa figura, está apresentada, além 
Figura 1: Probabilidades versus Taxas de Desconto.

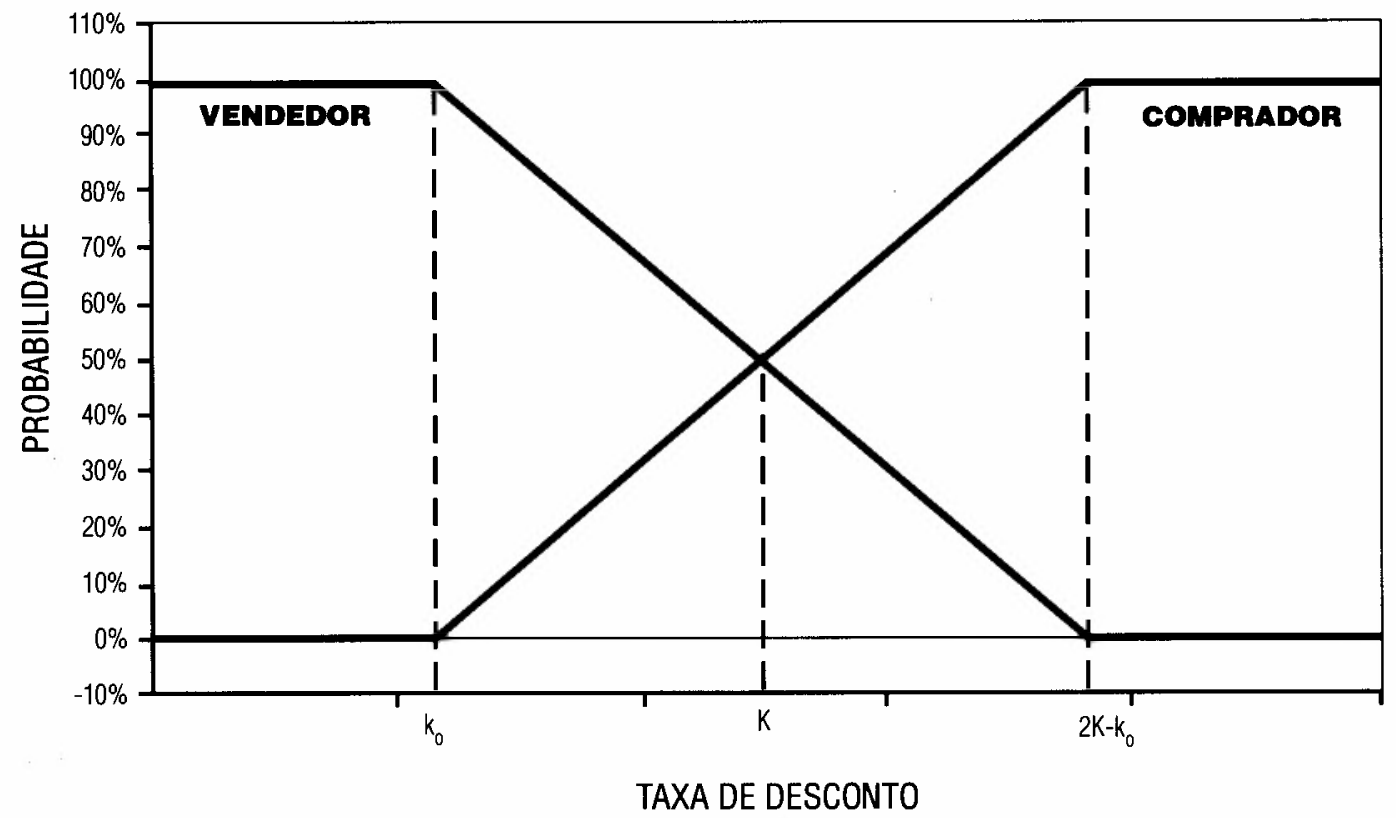

Figura 2: Probabilidades versus Valor.

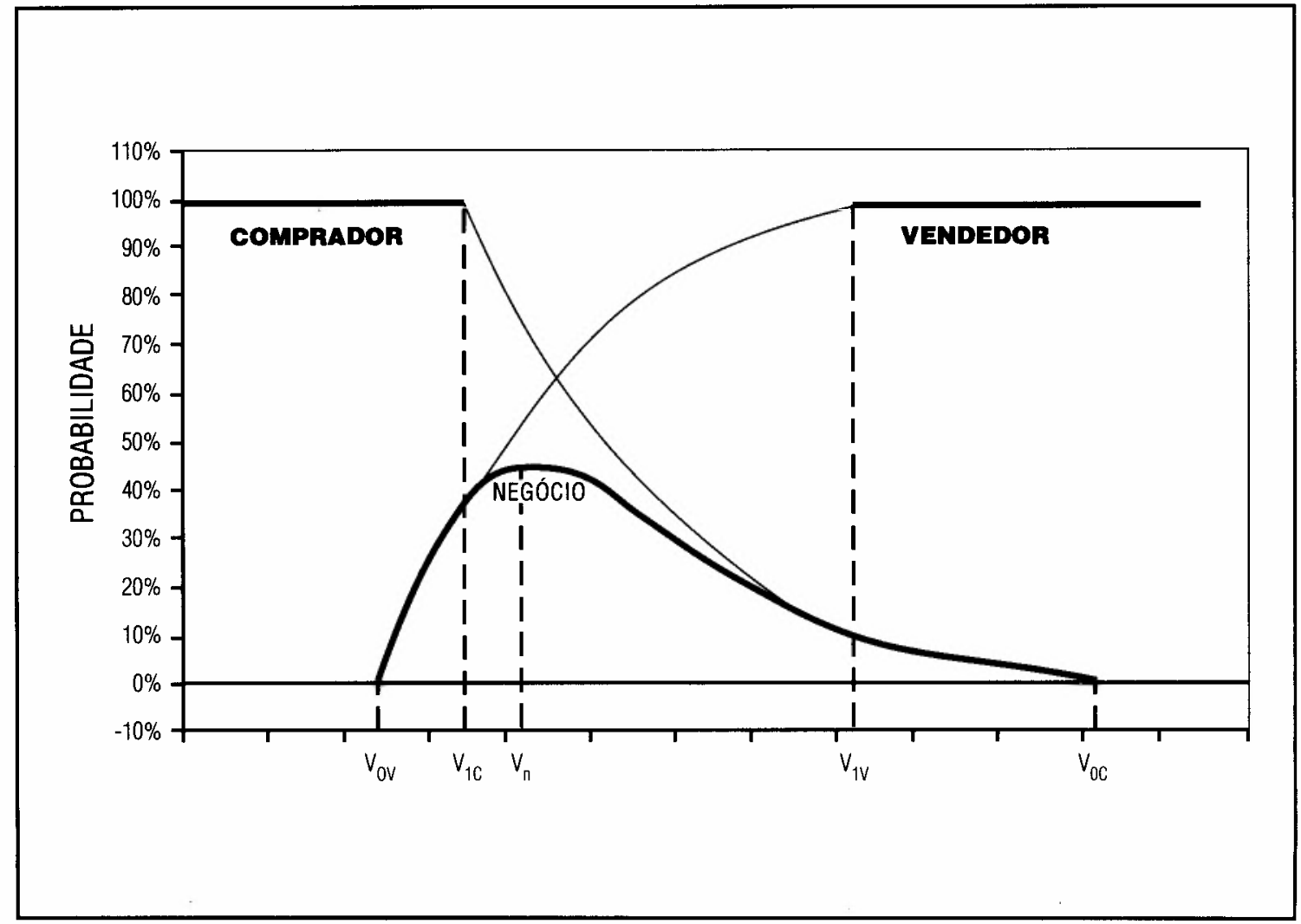


das probabilidades de o vendedor e de o comprador realizarem o negócio, o produto de ambas, que é a probabilidade do negócio efetivamente se realizar. $O$ valor $V_{n}$, para o qual a probabilidade de realização do negócio é máxima, é, por definição, o valor de mercado da empresa, resultado, portanto, da avaliação.

Se o fluxo futuro percebido pelo vendedor for uma perpetuidade de valor $F$, o fluxo do comprador pode ser expresso por s.F, onde s é $o$ fator de sinergia ( $>1$ ).

$\mathrm{Na}$ figura 2, os valores destacados têm os seguintes significados e expressões algébricas:

$$
\begin{gathered}
\mathrm{V}_{\mathrm{ov}}=\begin{array}{c}
\text { Valor abaixo do qual } \\
\text { o vendedor não } \\
\text { realiza negócio }
\end{array} \\
\mathrm{V}_{1 \mathrm{c}}=\underset{2 \mathrm{~K}-\mathrm{k}_{\mathrm{o}}}{\mathrm{O} \text { }} \\
\begin{array}{c}
\text { Valor abaixo do qual } \\
\text { com certeza }
\end{array}
\end{gathered}
$$

$\begin{gathered}\text { Valor mais provável } \\ \mathrm{V}_{\mathrm{n}}=\text { de realização do } \\ \text { negócio }\end{gathered}=\frac{2 . \mathrm{s} . \mathrm{F}}{\mathrm{k}_{\mathrm{o}}+\mathrm{s} .\left(2 \mathrm{~K}-\mathrm{k}_{\mathrm{o}}\right)}$

$$
\mathrm{V}_{1 \mathrm{v}}=\underset{\substack{\text { valor acima do qual } \\ \text { com certeza }}}{\mathrm{F} \text { condor vende }}=\frac{\mathrm{F}}{\mathrm{k}_{\mathrm{o}}}
$$

$$
\mathrm{V}_{\mathrm{oc}}=\underset{\begin{array}{c}
\text { Valor acima do qual } \\
\text { realiza negócio }
\end{array}}{\mathrm{s} . \mathrm{F}}
$$

Outra informação importante para o avaliador, além, naturalmente, do próprio valor da empresa, é a probabilidade de realização do negócio, para o valor calculado. Para o intervalo que vai de $V_{1 c}$ a $V_{1 v}$, a probabilidade de realização da transferência de controle da empresa, $\mathrm{P}_{n}$, é dada pelo produto de $\mathrm{P}_{\mathrm{c}}$ e $\mathrm{P}_{\mathrm{v}}$ :

$$
P_{n}=P_{c} \cdot P_{V}=\frac{s \cdot F-k_{0} \cdot V}{2 \cdot V \cdot\left(K-k_{0}\right)} \cdot \frac{F+V \cdot\left(k_{0}-2 K\right)}{2 \cdot V \cdot\left(k_{0}-K\right)}
$$

Se substituirmos $\mathrm{V}$ pela expressão de $V_{n^{\prime}}$ teremos:

$$
P_{n}\left(V_{n}\right)=\frac{\left(k_{0}-s \cdot\left(2 k-k_{0}\right)\right)^{2}}{16 . s .\left(K-k_{0}\right)^{2}}
$$

\section{VIÉS dO MÉTODO DO FLUXO DE CAIXA DESCONTADO E ASSIMETRIA DE RETORNOS PARA COMPRADORES E VENDEDORES}

Para o caso de uma perpetuidade, como a que serviu de base para as equações acima, $o$ método do fluxo de caixa descontado chegaria a um valor para a empresa de $\mathrm{F} / \mathrm{K}$. A relação entre o valor $V_{n}$ calculado acima e o valor obtido pelo FCD é, portanto:

$$
\frac{\mathrm{Vn}}{\mathrm{F} / \mathrm{K}}=\frac{2 \cdot \mathrm{s} \cdot \mathrm{K}}{2 \cdot \mathrm{s} \cdot \mathrm{K}-(\mathrm{s}-1) \cdot \mathrm{k}_{0}}>1 \text { para } \mathrm{s}>1 \text { e } \mathrm{k}_{0}>0
$$

É fácil observar que o valor estimado por essa teoria é tanto maior, em relação ao FCD, quanto maiores forem a sinergia e a taxa de juros da economia.

Calculemos agora a relação entre os ganhos dos acionistas minoritários da empresa adquirida e da adquirente, caso: (1) o mercado avalie o custo do capital da empresa adquirida, em média, pela taxa $K$; (2) o valor da aquisição seja $V_{n}$ e (3) a aquisição tenha correspondido a uma parcela $\mathrm{p}$ do capital da adquirente.

Nesse caso, a empresa adquirida, sob a nova gestão, passa a gerar um fluxo de recursos de s.F ao invés do antigo F. Portanto, ela sofre uma reavaliação automática, pelo mercado, de:

$$
r_{v}=\frac{s \cdot F / K-F / K}{F / K}=s-1
$$

que é o ganho dos acionistas minoritários da empresa adquirida, por ocasião da aquisição.

Os acionistas da empresa adquirente compraram, por $V_{n}$, um ativo que para eles vale, em média, s.F/K. Auferiram, portanto, um ganho com a transação, de:

$$
g=\frac{s \cdot F / K-V_{n}}{V_{n}}=(s-1) \cdot \frac{2 K-k_{0}}{2 K}
$$

Se, como foi suposto, a transação envolveu uma porção $\mathrm{p}(<1)$ do capital da empresa adquirente, o capital total da empresa deve sofrer uma reavalição imediata, em virtude do ganho com a aquisição, de:

$$
r_{c}=(s-1) \cdot \frac{2 K-k_{0}}{2 K} \cdot p
$$


A relação entre o retorno dos acionistas da empresa adquirente e o retorno dos acionistas da empresa adquirida é, portanto:

$$
r_{c} / r_{v}=\frac{2 K-k_{0}}{2 K} \cdot p<1 \text { para } k_{0}>0 \text { e } p<1
$$

A tabela 1 mostra valores médios de $\mathbf{p}$ para 770 aquisiç̧ōes.

Tabela 1: Estatísticas de Processos de Fusões nos EUA

\begin{tabular}{|c|c|c|}
\hline Década & $\begin{array}{c}\text { No de Aquis. } \\
\text { na amostra }\end{array}$ & $\begin{array}{c}\text { Mediana de } \\
\mathbf{p}\end{array}$ \\
\hline 1960 & 150 & 0,37 \\
\hline 1970 & 208 & 0,17 \\
\hline 1980 & 412 & 0,21 \\
\hline
\end{tabular}

FONTE: JARREL, G. \& POULSEN, A. Op. cit.

O gráfico da figura 3 mostra a relação $r_{c} / r_{v}$ em função de $K$, para um valor de $p=0,25$ e $\mathrm{k}_{\mathrm{o}}=5 \%$. A curva representa a expressão:

$$
r_{c} / r_{v}=1 / 4-1 /(160 . K)
$$

que para valores usuais de $\mathrm{K}$, entre $12 \%$ e $20 \%$, implica

$$
20 \%<r_{c} / r_{v}<22 \%
$$

\section{LIMITAÇ̃ES DA PRESENTE TEORIA E DESENYOLVIMENTOS FUTUROS}

As fórmulas obtidas a partir do modelo desta Teoria de Avaliação de Negócios baseiam-se em um fluxo perpétuo de valor constante. Para fluxos irregulares, como os que o avaliador encontra na prática, não há, naturalmente, fórmulas algébricas que determinem o valor da empresa e a probabilidade de realização do negócio.

Entretanto, o modelo exposto neste artigo tem demonstrado uma estabilidade muito grande face a oscilações na geração de recursos projetada.

Para exemplificar, geramos um fluxo aleatório para um horizonte de dez anos e adotamos um fator $s$ bastante alto, de 1.5, para obtermos grandes oscilaçōes na geração de re-

Figura 3: Relação $R_{C} / R_{v}$ versus $K$

CAP.ADQUIRIDA/CAP.ADQUIRENTE $=0,25$

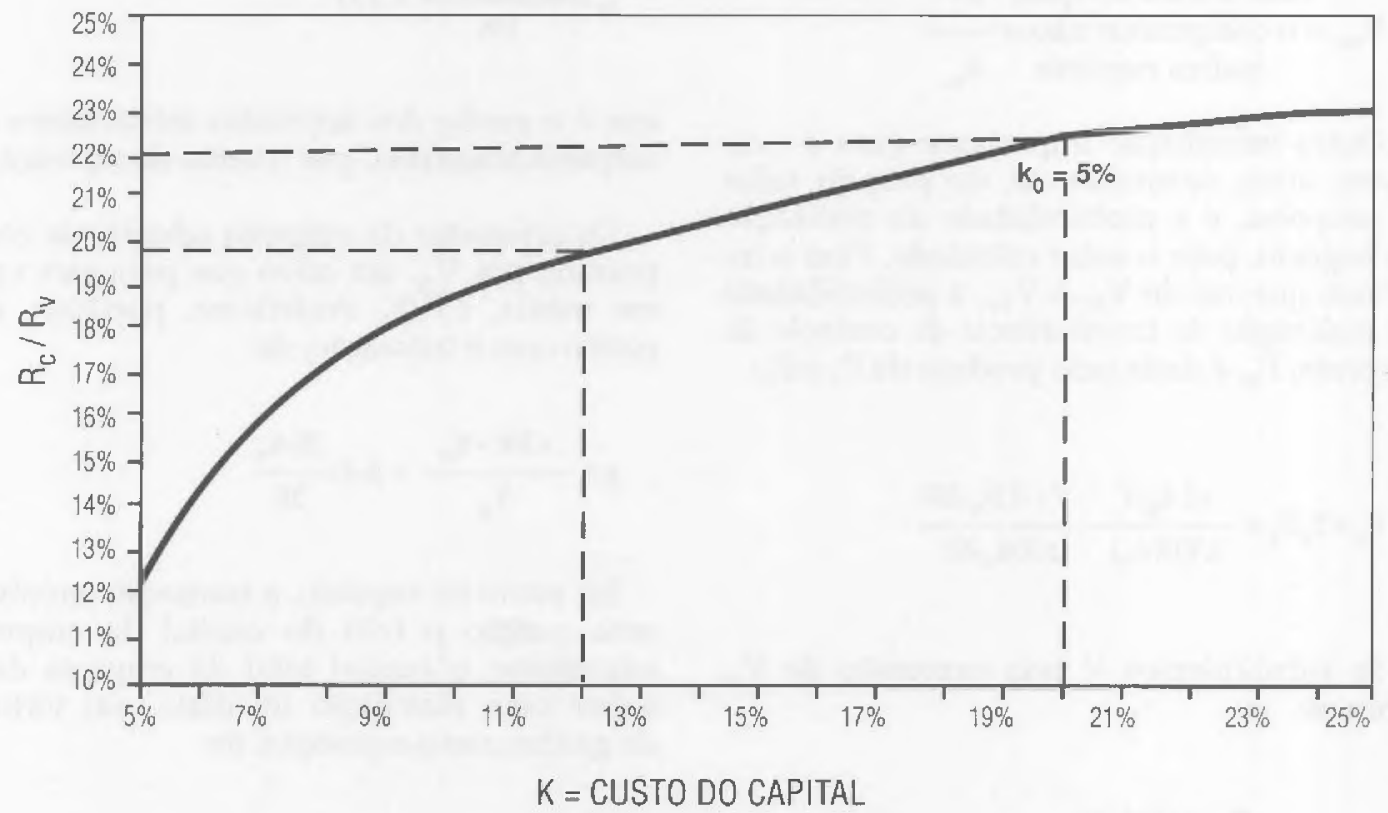




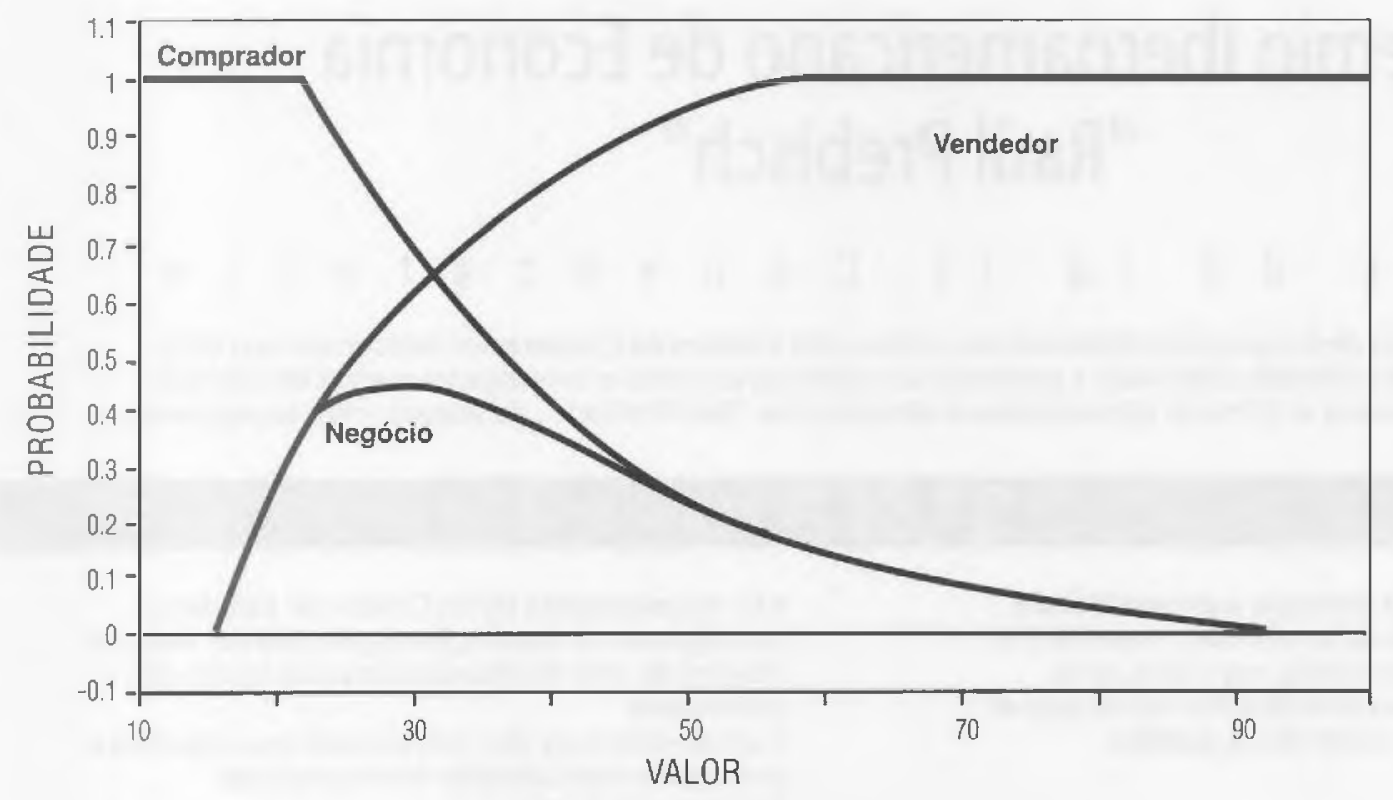

cursos projetada. Os resultados estão exibidos na tabela 2.

Tabela 2: Fluxos de Caixa para Comprador e Vendedor

\begin{tabular}{|c|c|c|}
\hline \multirow{2}{*}{ Ano } & \multicolumn{2}{|c|}{ Rendimentos para } \\
\hline & Vendedor & Comprador \\
\hline 1 & 8,0 & 12,0 \\
\hline 2 & 1,0 & 1,5 \\
\hline 3 & 3,0 & 4,5 \\
\hline 4 & 10,0 & 15,0 \\
\hline 5 & 9,0 & 13,5 \\
\hline 6 & 1,0 & 1,5 \\
\hline 7 & 4,0 & 6,0 \\
\hline 8 & 15,0 & 22,5 \\
\hline 9 & 3,0 & 4,5 \\
\hline 10 & 13,0 & 19,5 \\
\hline 11 a inf. & 10,0 & 15,0 \\
\hline
\end{tabular}

Adotando-se valores de $\mathrm{k}_{\mathrm{o}}=12 \%$ e $\mathrm{K}=25 \%$, obteve-se o gráfico da figura 4 . É bastante fá- cil determinar, por inspeçāo do gráfico, o valor do negócio. O programa que utilizamos para calcular o modelo desta Teoria estimou um valor de \$28 para esta empresa fictícia e probabilidades de $78 \%$ de encontrar um comprador que aceite esse valor e $57,6 \%$ de convencer o vendedor a vender a empresa por esse valor. (Não parece um negócio muito difícil de se intermediar.)

Deve-se observar a semelhança entre o gráfico da figura 4 e aquele da figura 2, o que demonstra a resistência do modelo a oscilações no fluxo.

Apesar de termos a impressão de que os problemas de subavaliação do FCD foram sanados com a teoria aqui exposta, não fomos bem-sucedidos em reproduzir a proporção entre os retornos dos acionistas de empresas adquiridas e adquirentes, reportados na literatura técnica americana.

Segundo Jarrell e Poulsen ${ }^{7}$, essa proporção situa-se entre $4,4 \%$ e $7,4 \%$, ao invés do que foi estimado neste artigo ( $20 \%$ a $22 \%$ ).

Acreditamos, contudo, que a direção apontada por esta Teoria esteja correta. Um possivel aperfeiçoamento deste modelo seria utilizar funções nāo lineares para correlação entre taxas de desconto e probabilidades de aceitação do negócio por parte do vendedor e do comprador. Esse procedimento introduziria um parâmetro a mais no modelo, que talvez explicasse a inconsistência em relação aos dados empíricos. $\square$
7. JARREL, Gregg \& POULSEN, Annette. Op. cit. 